\title{
Research on TalentsTraining Mode of Higher Vocational Education
}

\author{
Shuyu Shi ${ }^{1, a}$ \\ ${ }^{1}$ LiaoNing JianZhu Vocational University, Liaoning, Liaoyang, 111000 \\ 54892713@163.com
}

Keywords: Higher Vocational Education, TalentsTraining Mode

\begin{abstract}
Talents training model is the core element of personnel training in higher vocational education. Firstly, the paper studies the meaning of training model in higher vocational education, and then discusses the current situation and problems of personnel training mode of higher vocational education and analyze the reasons behind this problem. Finally, the paper proposes the optimization ways and measures of talents training mode in higher vocational education.
\end{abstract}

\section{Introduction}

Good training model for how to cultivate talent, what type of personnel training, both have a clear planning and evaluation criteria. On the one hand, in the economic globalization, talent training mode of higher vocational education in vocational education can learn from the experience of foreign countries, its essence and reject the dross; on the other hand, in the development of personnel training mode of higher vocational education We must face the shortage of educational resources, large population base of education, the education system imperfect reality.

In recent years, China has strongly advocated the development of vocational education, and a substantial increase in the number of higher vocational institutions, but also continue to expand the enrollment of the institutions, but this tends to bring down the expansion of the number of quality, resulting in the institutions of school conditions the relative weakening, operating efficiency is not high. Weaken and reduce the operating efficiency of school conditions make personnel training institutions in both lack of hardware support, and the lack of software assistance, ultimately in the position of a passive higher vocational education development. To ensure vocational education sustained, healthy and rapid development, it must be the school size, school structure, quality and efficiency of teaching harmonize, teaching reform must be safeguards, supporting policies and financial support to study and create distinctive professional training model.

\section{The Connotation of Higher Education Personnel Training Model}

In the current situation, the connotation of higher vocational and technical education training model includes the following specific points:

The purpose of vocational education. The purpose of education is to follow the education policy of the Party and the state for the construction of training model of talent to meet the social and economic development needs of talent. The purpose of the educational direction of teaching, teaching content, teaching methods and management plays a decisive role.

The pluralism of participation body. Vocational and technical education should be training to adapt production, construction, management and service needs of the application of the first-line personnel, training applied personnel must give full play to the role of schools, enterprises, economic entities and individual employers also should fully mobilize students initiative, to encourage students to actively participate, pluralism body also requires its training specifications and methods must be diversified.

The innovation of training model. Innovative vocational and technical education by the rapidity and talent market demand economic and technological development of the variability of the decision, the emphasis is practical, highlighting the innovative, the existing technical and vocational education personnel training model is the result of a long-term Theory and Practice of gradually forming the 
perfect result, the face of scientific and technological development, adjusting the industrial structure, upgrade the economic structure, personnel training model also requires constantly updated, constantly enrich and evolving, the only constant innovation Talents model is viable.

\section{The Problems of Personnel Training Model in Higher Vocational Education}

The training objectives is vague and the positioning is allowed. At present, China's key issues for which a higher vocational education level training, what type of talent, as well as the fate of post-graduate training and other personnel are blurred. In addition, both the society and the government, or schools, are on the higher vocational education training objectives misunderstanding. In: the community of higher vocational education is limited to admission of higher vocational education below the bachelor, and therefore, the position in the hierarchy is slightly lower than the average undergraduate, one chip; government and educational administrative departments in order to advance the process of popularization of higher education, having in expanding enrollment in higher vocational colleges a certain degree of blindness, lack of analysis of the vocational education training objectives particularity; the school does not have a correct understanding of the characteristics of higher vocational education and training objectives resulting in blurred.

The teaching concepts, methods and means are obsolete and lack of innovation is the center of personnel training. Students' knowledge of instructional design decisions width unreasonable instructional design is not conducive to students career awareness, resulting in students the theory and practice of touch, lack of innovation and creativity and so on. In addition, the tremendous impact of information technology on teaching methods and the way to bring also requires us to change the traditional teaching methods, the use of advanced multimedia technology and other teaching methods. Currently in China's higher vocational education, the traditional mode of education is still dominant. Teachers in teaching students more attention or knowledge to grasp the situation, they only pay attention to classroom teaching and teaching books, too much emphasis on the leading role of teachers to teach, resulting in outstanding personality, teaching methodology and innovative ability is nipped in the bud. In addition, the expense of the student teaching values, will, character, mental emotional ability, under the guidance of this teaching concept is difficult to adapt to the culture of human knowledge economy and information technology requirements.

The teaching theory and practice are imbalance. Currently focused on the theory and practice of light the shortcomings of many higher vocational institutions exist in the teaching. Many schools teaching model is completely copied the teaching mode colleges, leading students to book knowledge-based, "achievement-oriented", test scores first; some institutions due to lack of the necessary practice facilities and places for students unable to provide training base, as well as the practical aspects canceled. On the other hand, the school's teaching content and practice a serious gap, mainly in: (1)teaching content is not updated due to prolonged, resulting in school students knowledge and skills and the requirements of enterprises there is a big gap; (2) Vocational Schools contact teachers and fewer companies, mostly confined within the school of business and social needs no imagination to grasp in place, this theory of weak and strong features easily practice so that students in skills training and social practice out of touch, far unable to adapt to the trend of social development.

The low overall quality of graduates. Quality is the concentrated expression graduate school quality and reputation, the school is the lifeblood of existence and development. Higher Vocational Education as a special type of higher education, nature has its own unique quality standards. According to relevant statistics, China's higher vocational institutions training of personnel, in terms of the overall quality should be improved. Most companies generally considered higher vocational college students practical ability is low, before the formal hiring graduates have these "quasi-employees" for a month or even longer induction training; in addition, higher vocational colleges Training Students there are collective ideas weak, poor psychological quality, self-confidence is not strong, frustrated easily beat a retreat and other issues, leading to a lack of students' innovative spirit and practical ability. Some schools in personnel training followed the 
traditional mode of education to curb the imagination of students; some schools teaching in order to save costs, originally denied the right to belong to student internships or hands-on operation.

\section{The Causes of the Problems in Personnel Training Mode in Higher Vocational Education}

The lack of school hardware facilities. Although the State Higher Vocational Training Base building support and investment institutions is growing, but because of fewer large companies, exchanges between schools and enterprises is too small, the school practice base established employers pay to the enterprise substantial costs, existing school actually did not have the financial capacity, making school internship training base construction and practical training of students facing enormous difficulties. On the other hand, the establishment of simulation training base also need to spend huge amounts of money the school, the school's training base construction because of lack of funds are extremely limited, so that many students simply can not learn practical ability, highly skilled master it can not be implemented.

The teachers structure is irrational. For a long time, required teachers of higher vocational education is mainly relying on colleges and universities to develop. Teacher training objectives emphasis on discipline expert, follow the general pattern of higher education is to train teachers. Designed excessive pursuit of systematic training process and subject matter disciplines, refined, deep, ignoring the culture itself, application, practice and operational skills of higher vocational education. Train teachers of vocational education theory teaching only competent, incompetent teaching practice course, the lack of "double teacher" quality. The survey found that many schools in order to improve the employment rate of university students, had to "homegrown", this inbreeding phenomenon has seriously affected the teachers' education levels higher vocational colleges increased. Some higher vocational colleges because they can not meet the high level of talent out of the conditions, coupled with the influence of various factors concepts, treatment, etc., highly educated high-level personnel reluctant to higher vocational institutions engaged in teaching. Some colleges and universities in order to save expenditure on education, a low class fee to hire some non-good, non-professional part-time teachers, so that part-time teachers mixed fish heads, seriously affected the improvement of the quality of talent cultivation.

The quality students is low. Students of higher vocational education, mainly from secondary vocational school graduates, vocational high school graduates, high school graduates, but these three schools due to the running direction is inconsistent, and there is a great difference. Students basic theoretical foundation and professional levels of high school and vocational high school culture is relatively high, but the low level of professional skills; on the contrary, professional skills of students from secondary vocational schools of good quality, but relatively weak cultural foundation. For vocational institutions are concerned, to recruit different starting points, different qualities of students, is bound to give a unified examination and admission standards. Therefore, the quality of students vocational colleges face complex, uneven level groups, to build a reasonable training model, the task is arduous.

\section{The Optimization Ways and Measures of Personnel Training Mode in Higher Vocational Education}

Establish the concept of people-oriented and lifelong education. In the contemporary world rapid economic growth, industrial structure adjustment, the trend of frequent career changes, higher vocational education in an important position in the lifelong education system. Vocational College to establish the concept of lifelong education for workers throughout their careers, and give full play the advantages of multi-purpose school, in various forms, running a variety of modes, so that both academic education and vocational training, entrepreneurship, employment and training and job transfer, transfer of training and try to make the training objectives of higher vocational education by the simple skills for a career, extended to focus on the worker throughout his career skills and qualities. 
Establish the concept of vocational education which match our times. The current structure of our industry is labor-intensive and knowledge-intensive high-tech co-exist, but the high-tech development is bound to produce transition from labor-intensive to knowledge-intensive high-tech, increasingly high demand for workers, therefore, to Setting up the development of the times to match our concept of vocational education. Students of higher vocational education should be trained on the needs of the market, sought-after, high-quality workers have the skills or technology applied talents. They are required to master the basics enough, additionally need to have a strong ability to apply technology, even superb skills; they must also have good professional ethics and professionalism, with hard work, innovation and entrepreneurial spirit.

Establish quality education and creative talents cultivation. The current function of higher vocational education should simply imparting knowledge and application of knowledge of both the steering vigorously students actively acquire and apply new knowledge capability information, namely creativity. Higher Vocational Education to pay special attention to cultivating students' independent thinking ability, outstanding knowledge of new processing and re-creation of training capacities, to encourage students to actively participate in the teaching process, effective learning methods to master. Make them learn how to learn, learning to do, learning to collaborate, learn development, learn to predict, anticipate and ideas, develop students' divergent thinking ability, enhance their initiative and creativity, lay the foundation for lifelong learning and education, so that they can continue learning to consistently create better adapt to the development of innovative economy.

\section{Conclusion}

The talents cultivated in higher vocational education are in high demand and are most widely used in the national economy and they are the application type and skill type talents who are different from academic personnel trained in ordinary universities. They play an important role in national economic development and promotion the science and technology into productivity. In 21 century, vocational education is facing unprecedented development space, in front of the great development opportunity, in order to gain a firm foothold in higher education, we must optimize the training mode in higher vocational education.

\section{References}

[1] J.Zhang, The thought on the talent cultivation aim of higher education, J. Vocational and Technical Education. 19(2003) 115-120.

[2] Y.G.Qi, The research on the system framework construction of the quality education, J. Educational Research. 1(2000) 58-63.

[3] Z.M.Deng, The comparative and innovation research in higher vocational technical education model, J. Vocational Education Forum, 20(2002) 62-65.

[4] X.M.Jiang, Higher employment-oriented specialty programming, J. Vocational and Technical Education, 4(2005) 101-105.

[5] N.L.Miu, The comparison of foreign vocational training model, J. Vocational Technical Education Forum, 12(2004) 124-126. 